\title{
Efficient institutions and effective deterrence: on timing and uncertainty of punishment
}

\author{
Johannes Buckenmaier* \\ University of Cologne
}

Ann-Christin Posten

University of Cologne

\author{
Eugen Dimant \\ University of Pennsylvania \\ CeDEx \\ Ulrich Schmidt \\ Kiel Institute for the World Economy \\ University of Johannesburg \\ University of Kiel
}

\begin{abstract}
We carry out the first controlled economic experiment to study the effectiveness of swiftness of punishment in reducing illicit behavior. We consider two dimensions: timing of punishment and timing of the resolution of uncertainty regarding the punishment. We find a surprising inverted u-shaped relation between deterrence and the delays of punishment and uncertainty resolution. Institutions that either reveal detection and impose punishment immediately or maintain uncertainty about the state of detection and impose punishment sufficiently late are equally effective at deterring illicit behavior. Our results yield strong implications for the design of institutional policies to mitigate misconduct and reduce recidivism.

Keywords: Experiment; Illicit Behavior; Institutions; Punishment; Swiftness; Uncertainty

JEL: C91, D02, D81, K42
\end{abstract}

\section{Introduction}

Governments all over the world use substantial resources to keep society safe and punish people for criminal acts. Annually, the US spends approximately $\$ 75$ billion on

${ }^{*}$ E-Mail of corresponding author: johannes.buckenmaier@uni-koeln.de. We would like to thank Dan Ariely, Gary Bolton, Catherine Eckel, Simon Gächter, Kyle Hyndman and David Rand for helpful remarks and input. We would also like to thank participants at workshops and conferences, most notably the CESifo Venice Summer Institute 2016, the Norms, Actions Games Workshop at the Institute for Advanced Study, the Morality, Incentives and Unethical Behavior Conference at UCSD as well as invited talks at the London School of Economics (Behavioral Science Hub), Yale University (Human Cooperation Laboratory), University of Pennsylvania (Solomon Laboratories of Experimental Psychology) for fruitful discussions. Generous financial support through the Edmond J. Safra Center for Ethics at Harvard is greatly appreciated. 
incarceration (not including costs for courts, trials, etc.). Thus, it is hardly surprising that extensive research has been done to understand the determinants of deviant behavior and shed light on alternative deterrence mechanisms. Existing economic literature not only stresses the relevance of institutional environments in shaping prosperity and growth (La Porta et al., 1999; Acemoglu et al., 2005), but also their importance in effectively deterring criminal and immoral behavior in ways that include staff rotations in public administration, crown witness regulations, and changes in punishment regimes (Shleifer and Vishny, 1993; Abbink, 2004; Abbink et al., 2014; Engel et al., 2016; Buckenmaier et al., 2017). Due to the inherent methodological challenges of studying deviant behavior, where reliable observational data is unavailable, economists have turned to controlled experiments to address these pressing questions (Abbink, 2006). We follow this methodological approach in our paper.

There is a vast literature on criminal deterrence that focuses on the relevance of the certainty and severity of punishment in deterring deviant behavior (see e.g. Becker, 1968; Baker et al., 2004; DeAngelo and Charness, 2012; for a recent review of economic research see Chalfin and McCrary, 2017 and for a cross-disciplinary discussion of experimental work see Engel, 2016). However, the swiftness of punishment (often referred to as celerity), frequently mentioned alongside certainty and severity (Bailey, 1980; Howe and Brandau, 1988; Yu, 1994; Nagin and Pogarsky, 2001, 2004), has been under researched by those in the economic field. Understanding the mechanisms underlying deterrence of deviant behavior yields important policy implications. Given the high costs involved in increasing punishment's certainty (e.g. costs for an executive body) or punishment's severity (e.g. incarceration costs), we argue that the timing of conviction and punishment, that is, their delay with respect to the transgression in question, can potentially serve as a powerful tool for deterrence that is often available at a relatively low cost.

The classic theoretical approach towards the deterrence of criminal activity (e.g. Becker, 1968) is based on the assumption that potential offenders mainly weigh the potential gains against the potential adverse consequences of an offense. In the standard framework of discounted expected utility, delayed punishment should reduce deterrence due to a discounting effect, whereas the timing of resolution of uncertainty should have no effect on behavior. Starting with the seminal paper of Loewenstein (1987), several theories propose that anticipation of future events is an important determinant of intertemporal utility (see e.g., Wu, 1999; Lovallo and Kahneman, 2000; Caplin and Leahy, 2001; Dillenberger, 2010; Strzalecki, 2013; Golman and Loewenstein, 2015). These models are based on the idea that a non-negligible proportion of the overall consequences from future consumption (be it negative or positive) is already consumed in the form 
of so-called anticipatory utility before actual consumption takes place. While there is growing theoretical literature supporting anticipatory utility theory and its implications, there is little empirical work being done and even less experimental investigation. ${ }^{1}$

The goal of the present paper is to experimentally test the implications of anticipatory utility in the context of institutional deterrence mechanisms. In particular, we are interested in how the timing of sanctions (be it conviction or sentencing) and the timing of the resolution of uncertainty surrounding these sanctioning mechanisms affects deterrence. We systematically vary the celerity of a sanction within a new, stylized, experimental paradigm along the following two dimensions: first, we vary the delay between offense and detection/conviction; second, we vary the delay between offense and sanctioning. Our main objective is to better understand the role of celerity, in our opinion, an important dimension of most deterrence mechanisms, that has received surprisingly little attention in previous literature. We argue that celerity could potentially serve as a useful tool for policy makers to design more efficient and/or less expensive institutional deterrence mechanisms. However, delayed punishment is not necessarily less deterrent (due to discounting) if utility from anticipation is taken into account. Additionally, we study the role of the timing of resolution of uncertainty. We vary the point in time when the information about whether or not a transgression was detected is revealed to subjects. We show that in theory, depending on the impact of anticipatory utility, delayed resolution of uncertainty may increase deterrence.

Our experimental analysis is based on a simple guessing game where subjects may cheat in some periods to increase payoffs. After these periods there is an investigation such that cheaters will be detected and fined with a given probability. In the single treatments, we vary both the timing of the potential fine, as well as, the timing of the resolution of uncertainty, i.e. when the participants learn the results of the investigation. We analyze behavior alongside two dimensions: total cheating behavior and recidivism (conditional cheating). Our results show that delayed resolution has no systematic impact on cheating. With respect to the relation between the delay of punishment and deterrence, we observe an inverted u-shape relationship where deterrence is lowest for a short delay of punishment and significantly lower for either no delay or a long delay when combined with a late resolution of uncertainty.

This result is at odds with discounted expected utility and theories of anticipatory utility, but can be explained by the recent model of Baucells and Bellezza (2016). They extended anticipatory utility by a reference point, a utility of recall and a magnitude

\footnotetext{
${ }^{1}$ Two recent exceptions are Falk and Zimmermann (2016), who experimentally tested the implications of anticipatory utility in the context of information preferences and Kogler et al. (2016), who showed that delayed resolution of a tax audit results in higher tax compliance.
} 
effect in discounting. We conclude that in order to increase the deterrence of sanctioning mechanisms, punishment should either be swift or sufficiently delayed and paired with the psychological dread of uncertainty.

The paper is organized as follows. The next section provides a brief review of the theoretical and empirical background on the relation between celerity and deterrence. Section 3 details our experimental procedures and discusses the hypotheses we aim to test. Results are presented in Section 4. The final section discusses our results and derives some conclusions.

\section{Theoretical and Empirical Background}

The benefits of criminal behavior are usually immediate. Any proceeding detection, conviction, and implementation of legal consequences are generally delayed and stochastic. This poses an inter-temporal decision problem under uncertainty. Classically, celerity meant only the temporal delay of a potential sanction following a transgression. We will adopt a wider definition of celerity, using it as a catch-all phrase for the timing of the various facets of a deterrence mechanism. There are several prominent economic theories of inter-temporal decision making. Here we want to focus on two. First, theories of temporal discounting suggest that future costs or benefits receive a lower weight than immediate ones; this weight decreases as one moves further into the future (Frederick et al., 2002). The implications are simple. If a potential offender discounts delayed legal consequences, then deterrence decreases the longer the delay. As a consequence, higher celerity (less delay) would increase the efficiency of legal sanctions, which is the classical hypothesis in criminological literature (Nagin and Pogarsky, 2004; Paternoster, 2010).

Second, theories of anticipatory utility that incorporate anticipatory feelings such as excitement, fear or dread into classical expected utility theory suggest that one might want to bring forward an unpleasant event to shorten the period of dread (or delay a positive event to enjoy the excitement for a longer period of time). The idea is that future events influence current utility. More precisely, negative (positive) future events cause negative (positive) utility today the further away the event is (at least up to a certain point). Caplin and Leahy (2001) extend Loewenstein's model by allowing for uncertainty and point toward the importance of anticipatory feelings prior to the resolution of uncertainty. However, anticipatory emotions, such as anxiety, are often predicated on an uncertain future. Thus, they are mainly relevant prior to the resolution of uncertainty. This suggests that the point in time at which uncertainty is resolved is particularly important. For example, Kreps and Porteus (1978) and Kocher et al. (2014) show that 
preferences over temporal lotteries also depend on the point in time when the uncertainty is resolved. That is, agents can show a preference for earlier or delayed resolution of uncertainty. Further evidence comes from consumer literature. Anticipatory emotions, compared with outcome-based emotions, are central in prospective consumption situations. Furthermore, the uncertainty associated with anticipatory emotions negatively affects intentions (Bee and Madrigal, 2013). Psychological learning theories (Skinner, 1963; Tversky and Kahneman, 1986; Ehrlich, 1996; Hackenberg, 2009) second the argument that the time between a transgression and the punishment and the uncertainty that is associated with the punishment are driving forces for effective behavioral changes. If this is indeed the case, then the classical interpretation of celerity as the time between committing an offense and the actual punishment (e.g. fine or imprisonment) should be complemented by the time the uncertainty is resolved, thus, the time of sentencing.

The implications of the timing of a sanction on deterrence derived from anticipatory utility theory could oppose those suggested by temporal discounting. Clearly this is an important point that has to be taken into consideration for the design of legal institutions. A systematic study of the role of celerity for deterrence poses a serious empirical challenge, because changing the celerity of an enforcement mechanism would most likely impact existing institutional structures on multiple levels. For that reason, isolating the impact of such an intervention is hardly possible in the field. In addition, it is unclear whether an actual or would-be offender is aware of this change or not, making identification almost impossible. Thus, a systematic study of celerity calls for a highly controlled environment that allows for the isolation of the direct effect of institutional changes varying celerity on behavior. Fortunately, the experimental laboratory provides such a controlled environment.

\section{Design and Hypotheses}

\subsection{Experimental Design}

We use a simple guessing game that is played repeatedly by our subjects for a total of 28 rounds. In certain rounds subjects are presented with the option to "cheat". Cheating guarantees them the maximum possible payoff for that round. Our goal was to design a simple game where the option to cheat was not integral; we wanted the game to be easy-to-understand, but meaningful regardless of whether or not the option to cheat was presented. Specifically, we wanted to make sure that cheating was not considered part of the game, but a clear violation of said games rules. In our guessing game a card is randomly drawn from a deck of 32 cards and subjects have to guess which card was 
drawn. A subject received 10 Experimental Currency Units (ECU) for a correct guess and 4 ECU for an incorrect guess. In some rounds participants are given the option to cheat. By cheating, participants are allowed to uncover the randomly drawn card before making one's guess, ensuring a correct answer and the maximum payoff of 10 ECU less a possible fine if detected. ${ }^{2}$ Participants were informed that each instance of cheating would be followed by an "investigation" that would detect cheating with a fixed probability of $25 \%$. Hence, cheating exposes them to the risk of being caught. If caught the consequences are two-fold. First, the subject has to pay a fine of 10 ECU. Second, the subject is suspended from the game for one round, is not allowed to make any decision and cannot earn any ECU. Furthermore, suspended participants are forced to wait 60 seconds before they are allowed to continue in the next period. We deliberately chose suspension as part of the sanctioning mechanism to increase salience with regard to the timing of sanctions. While one might argue that a delayed fine in a laboratory context where all "actual" payments are realized at the very end of the experiment decreases the result's robustness, such concerns do not apply to the suspension as it is clearly linked to the particular round a subject is suspended.

In order to make the moral dimension of cheating more salient in our laboratory context we introduce a third party, represented by a charity, that incurs a monetary damage as a result of cheating. Specifically, for each experimental session there is a charity pool of $250 \mathrm{ECU}$ (worth \$25) from which $50 \mathrm{ECU}$ is deducted each time a particular subject decides to cheat. At the end of the experiment one subject is randomly selected whose decisions determine the charity pool, the remainder of which will be donated to "Doctors without Borders".

In our experiment, we vary the timing along the following two dimensions: the timing of punishment and the timing of the resolution of uncertainty. Punishment is either immediate, delayed by 2 rounds or delayed by 4 rounds. In addition, the resolution of uncertainty regarding whether cheating is detected (and hence whether there are sanctions) is either immediate or delayed by two periods. To ensure that later cheating decisions are not affected by unresolved risk each cheating decision was followed by five rounds without cheating. ${ }^{3}$

All treatments consist of 28 rounds: 4 training rounds followed by 4 blocks of 6

\footnotetext{
${ }^{2}$ When subjects decide to cheat, we automatically implement the "right guess" for them. Subjects are informed about this procedure in the instructions. We implement this forced guess to avoid "second thoughts" where a subject cheats, views the drawn card, but chooses a different card.

${ }^{3}$ For each subject there were exactly four cheating opportunities, that is, in rounds 5, 11, 17 and 23 subjects were given the opportunity to cheat. Subjects were told that, "occasionally", they will be presented with the option to cheat, but they were informed about the exact timing and frequency of the occurrence of this option.
} 
rounds each. In the first 4 rounds participants play the guessing game without cheating to familiarize themselves with the game and the interface. In the first round of each block subjects can cheat. In the remaining rounds of a block (rounds 2-6) they play the guessing game without the option to cheat. Using blocks of 6 rounds allows us to vary both the timing of the resolution of uncertainty, as well as, the timing of punishment without an overlap with subsequent cheating decisions.

Table 1: Overview of timing of resolution of uncertainty and punishment in the different treatments.

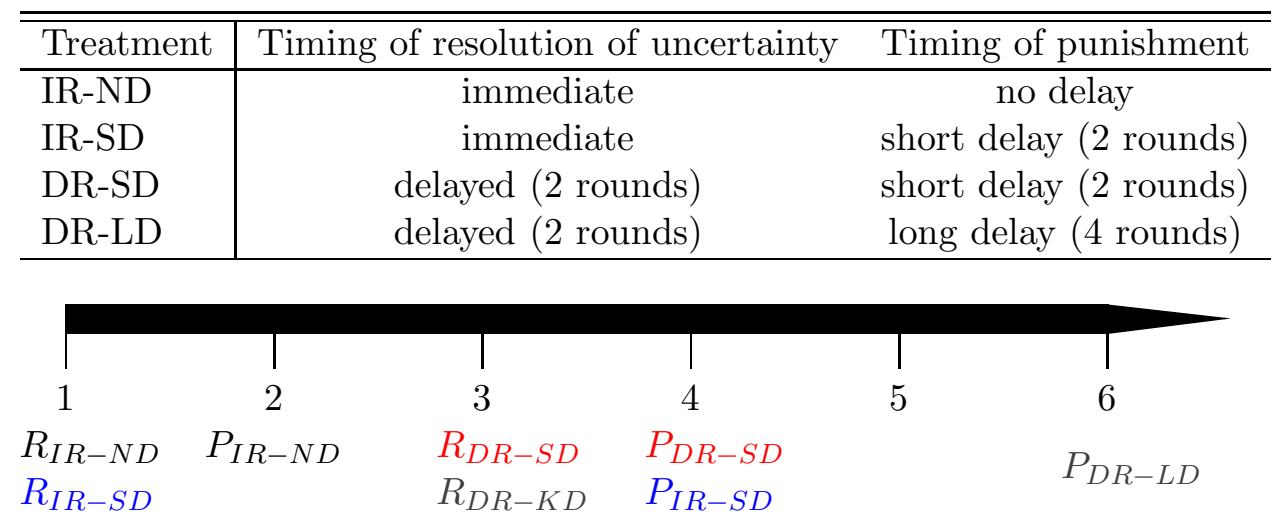

Note: In the timeline $P$ and $R$ indicate the timing of resolution of uncertainty and timing of punishment for $I R-N D, I R-S D, D R-S D$, and $D R-L D$, respectively.

Table 1 summarizes the four treatments. In treatment $I R$ - $N D$, we have immediate resolution of uncertainty and no delay of punishment. Subjects receive immediate feedback within the same round about whether cheating was detected and there is no delay in punishment. That is, the fine (if due) is deducted and a potential suspension is implemented immediately for the next period. ${ }^{4}$ In treatment $I R$ - $S D$, resolution of uncertainty is again immediate, but now there is a short delay in punishment of two periods; when cheating in period $t$ the uncertainty will be resolved immediately, but the potential fine and suspension are executed only in period $t+3$ (as opposed to $t+1$ in $I R$ $N D$ ). We will also refer to $I R-S D$ as immediate resolution of uncertainty and short delay of punishment. In treatment $D R$ - $S D$, the investigation into cheating does not conclude immediately, but lasts for two additional periods. Only after that is the participant informed about whether his cheating was detected or not. As in $I R-S D$, there is a short delay of punishment. We hence refer to $D R-S D$ as delayed resolution of uncertainty and short delay of punishment. Finally, in treatment $D R-L D$ resolution is again delayed, but

\footnotetext{
${ }^{4}$ Clearly punishment cannot precede the resolution of uncertainty which determines whether a subject was detected and hence will have to face a punishment.
} 
now punishment is delayed for four periods rather than two. That is, cheating in period $t$ results in resolution of uncertainty in period $t+2$, followed by the actual punishment (if due) in period $t+5$.

\subsection{Experimental Procedures}

We conducted 32 experimental sessions at the Decision Science Lab at Harvard University. Participants were recruited vie e-mail invitation from the laboratory's database which contains students, as well as, non-students. A total of 296 subjects (out of which $46.6 \%$ were males) participated in the experiment split between treatments as follows: 66 subjects in $I R-N D, 85$ subjects in $I R-S D, 69$ subjects in $D R-S D$ and 76 subjects in $D R$ - $L D$. The experiment was programmed and run using z-Tree (Fischbacher, 2007). ${ }^{5}$ Within each session participants were randomly assigned to a computer booth in which they would participate in the experiment anonymously. The consent forms and instructions for the corresponding treatment were distributed. ${ }^{6}$ Upon agreeing to the informed consent page the participants were given sufficient time to read the instructions carefully. Before the start of the experiment subjects had to answer a series of comprehension questions in order to check their understanding of the game and its payoff structure. Subjects then played 28 periods after which they were informed of their total earnings via a detailed summary screen. One subject was randomly drawn to determine the charity pool and all participants were informed about the final amount left in the pool to be donated to "Doctors without Borders". ${ }^{7}$ At the end of the experiment subjects completed a questionnaire containing questions on personal characteristics (demographics, education, income, age), risk-attitudes (SOEP), consideration of future consequences (Strathman et al., 1994) and self-control (Tangney et al., 2004).

Sessions lasted approximately 45 minutes excluding the time for payment. A participant's payoff was determined by the sum of his earnings over all 28 rounds. The total payoff in ECU was then converted to dollars at a rate of $10 \mathrm{ECU}=\$ 1$. The average payment was $\$ 14.29$ which includes a show-up fee of $\$ 2.50$.

\footnotetext{
${ }^{5}$ It is worth noting that we observed an influx of disproportionately older participants due to a bug in the recruitment software in our first sessions. This was quickly resolved. Participants of 41 years and older represent around $11 \%$ of our data set. Unless noted otherwise, our results are robust with respect to this subgroup.

${ }^{6}$ The original instructions are provided in Appendix A.

${ }^{7}$ Prior to the experiment subjects received a short description of the work of "Doctors without Borders"'. Although we cannot know for sure that all participants endorse their work, we wanted to enforce a minimal level of common knowledge to increase salience. A receipt of the amount actually donated was made available to all participants via email.
} 


\subsection{Hypotheses}

In this section, we further detail our main hypothesis on how deterrence could be affected by the delay of punishment and the timing of resolution of uncertainty. In the standard discounted expected utility (DEU) model, optimal decisions do not depend on the timing of resolution of uncertainty. In our model a delay of punishment should decrease deterrence. The utility of not cheating $(N C)$ is identical in all treatments and is given by

$$
\operatorname{DEU}(N C)=\frac{31}{32} 4+\frac{1}{32} 10
$$

where we assume for convenience a linear utility function. ${ }^{8}$ We restrict attention to a single block consisting of 6 periods, where cheating was possible in the first round of that block. Further, we only consider the utility generated from the decision about cheating in the first period of such a block in all our analyses. The remaining utility components within a block are identical across treatments. In the baseline treatment, detected cheaters are fined (10 ECU plus one round suspension) directly in the next period. For a discount factor $\delta<1$, the utility of cheating $(C)$ amounts to

$$
\operatorname{DEU}(C, \mathrm{IR}-\mathrm{ND})=10-\frac{1}{4} \delta(10+\operatorname{DEU}(N C))
$$

as cheating is not possible in the next period. Compared to the baseline treatment, punishment is delayed by two further periods in $I R-S D$. The same is true for $D R-S D$. As the timing of resolution of uncertainty is immaterial under DEU, we get

$$
\operatorname{DEU}(C, \mathrm{IR}-\mathrm{SD})=\operatorname{DEU}(C, \mathrm{DR}-\mathrm{SD})=10-\frac{1}{4} \delta^{3}(10+\operatorname{DEU}(N C)) .
$$

Finally, we have

$$
\operatorname{DEU}(C, \mathrm{DR}-\mathrm{LD})=10-\frac{1}{4} \delta^{5}(10+\operatorname{DEU}(N C)) .
$$

as punishment is delayed by a total of four periods in $D R-L D$.

Since $\operatorname{DEU}(C, \mathrm{IR}-\mathrm{ND})<\operatorname{DEU}(C, \mathrm{IR}-\mathrm{SD})=\operatorname{DEU}(C, \mathrm{DR}-\mathrm{SD})<\operatorname{DEU}(C, \mathrm{DR}-\mathrm{LD})$ where the utility of not cheating is independent of the treatments, we get the following hypothesis:

Hypothesis 1. Increasing the delay of punishment decreases deterrence, leading to more violations in $I R-S D$ compared to $I R-N D$ and in $D R$ - $L D$ compared to $D R-S D$.

\footnotetext{
${ }^{8}$ While risk aversion modeled by a concave utility function certainly influences the decision between cheating and not cheating, it does not imply differences between treatments.
} 
Hypothesis 2. The timing of resolution of uncertainty does not affect behavior, implying that violations in Treatments $I R-S D$ and $D R-S D$ are identical.

Hypothesis 3. Since the timing of resolution of uncertainty does not change deterrence and increasing the delay of punishment decreases deterrence, we will have more violations in $D R-S D$ than in $I R-N D$ and more violations in $D R-L D$ than in $I R-S D$.

Following Loewenstein (1987) negative future outcomes can cause immediate disutility through negative anticipatory emotions such as fear, dread or anxiety. DEU fails to take this into consideration. Suppose you were cheating in the baseline treatment. Then you dread in the first period that you will be fined in the next one, i.e. you dread a loss of $10+\operatorname{DEU}(N C)$. For a discount rate $\gamma$ which measures the degree to which current utility is influenced by anticipated emotions from consumption in the next period, the utility of cheating is given by

$$
\mathrm{UAE}(C, \mathrm{IR}-\mathrm{ND})=10-\frac{1}{4}(\delta+\gamma)(10+\operatorname{DEU}(N C))
$$

where UAE denotes utility with anticipated emotions. We now consider IR-SD where there is a short delay of punishment by two periods. Note that the utility from anticipation is discounted with discount factor $\delta$. While the discounting effect in (3) increases utility compared to $I R-N D$, anticipation leads to decreasing utility as dread is now experienced in more than one period. More specifically, we get

$$
\mathrm{UAE}(C, \mathrm{IR}-\mathrm{SD})=10-\frac{1}{4} \delta^{3}(10+\mathrm{DEU}(N C))-\frac{1}{4}\left(\gamma^{3}+\delta \gamma^{2}+\delta^{2} \gamma\right)(10+\mathrm{DEU}(N C))
$$

Comparing (5) and (6), it may well be that the utility of cheating is lower in $I R$-SD than in $I R-N D$ if $\gamma$ is sufficiently high. Since the utility of not cheating is identical across treatments, we get as alternative to Hypothesis 1,

Hypothesis $1^{*}$. If the effect of anticipation is sufficiently high, delaying punishment increases deterrence leading to less violations in $I R-S D$ compared to $I R-N D$ and in $D R$ $L D$ compared to $D R-S D$.

Anticipated emotions in the model of Loewenstein (1987) refers to future consumption under certainty. In Treatments $D R-S D$ and $D R-L D$ resolution of uncertainty is delayed which may alter anticipatory emotions. While in $I R-S D$ a detected cheater may feel dread in periods 1-3 due to anticipating the punishment in period 4 , in $D R-S D$ a cheater may experience the anxiety of being detected in the later investigation. Following Caplin and Leahy (2001) the anxiety experienced one period before resolution 
should depend on the probability of being detected and the size of the fine. As all these parameters are identical in Treatments $D R-S D$ and $D R-L D$ we simply use the terms $A$ to denote the anxiety of a cheater one period before resolution. We now introduce a third discount rate $\alpha$, such that anxiety experienced $t$ periods before resolution is given by $\alpha^{t} A$. This yields the following utility of cheating in $D R-S D$ :

$$
\mathrm{UAE}(C, \mathrm{DR}-\mathrm{SD})=10-\frac{1}{4} \delta^{3}(10+\mathrm{DEU}(N C))-\left(\alpha+\delta \alpha^{2}\right) A-\frac{1}{4} \delta^{2} \gamma(10+\mathrm{DEU}(N C))
$$

Typically, it is observed that people prefer early resolution of uncertainty for negative outcomes. In our model this is the case if

$$
\left(\alpha^{2}+\delta \alpha\right) A>\frac{1}{4}\left(\gamma^{3}+\delta \gamma^{2}\right)(10+\operatorname{DEU}(N C))
$$

and leads to the following hypothesis:

Hypothesis 2*. Delayed resolution of uncertainty increases deterrence leading to less violations in $D R$-SD compared to $I R-S D$.

Obviously, if the resolution of uncertainty should be delayed in order to increase deterrence, punishment has to be delayed as it cannot precede the resolution of uncertainty. The combined effect of delayed resolution and delayed punishment can be grasped by comparing $D R-S D$ to $I R-N D$. If both delaying punishment according to Hypothesis $1^{*}$ and delaying resolution according to Hypothesis $2^{*}$ increases deterrence, our model implies the following:

Hypothesis 3*. If delaying punishment increases deterrence due to dread and delayed resolution also increases deterrence due to anxiety, then the combined effect of delaying punishment and resolution results in less cheating and, therefore, less violations in $D R$ $S D$ compared to $I R-N D$.

Let us finally consider the utility of cheating in $D R-L D$. Here we get

$$
\mathrm{UAE}(C, \mathrm{DR}-\mathrm{LD})=10-\frac{1}{4} \delta^{5}(10+\bar{u})-\frac{1}{4}\left(\gamma^{3}+\delta \gamma^{2}+\delta^{2} \gamma^{3}+\delta^{3} \gamma^{2}+\delta^{4} \gamma\right)(10+\bar{u})
$$

The cheater experiences anxiety prior to the resolution of uncertainty as in $D R-S D$, but there is also an extended period where he may experience dread due to delayed punishment. The second component is similar to the dread experienced in $I R-S D$, additionally discounted as the experience starts two periods later. Assuming (8), a comparison of (9) and (6), reveals that the utility of cheating in $D R-L D$ will be smaller than that of 
cheating in $I R-S D$ under the conditions of Hypothesis $1^{*}$. This results in the following hypothesis:

Hypothesis $4^{*}$. If (8) holds and the effect of anticipation is sufficiently high $(\gamma$ is large enough), then delayed resolution combined with delaying punishment results in less cheating leading to less violations in $D R-L D$ compared to $I R-S D$ and less violations in $D R$ - $L D$ compared to $I R-N D$.

\section{Results}

Here, we present our results using parametric and non-parametric comparisons, ${ }^{9}$ as well, various regression techniques to analyze differences in cheating behavior, as motivated by our hypotheses. Please note that not only the number of cheating opportunities (4) were the same in all treatments, but also their timing (always in the first round of each block). Hence, any difference in behavior can only result from our systematic variation in the timing of punishment and the timing of resolution of uncertainty.

First, we look at the mean differences in total cheating across all treatments as outlined in the theory part of our paper. Total cheating is defined as the total number of individual cheating incidences across all rounds. We calculate the percentage as the ratio of actual individual cheating decisions to the maximum possible number of cheating opportunities (4). We present the test results in Table 2 and a graphical illustration in Figure 1. Results illustrate that the amount of cheating is 15 percentage higher in $I R$ $S D$ when compared to cheating in $I R-N D$ (BSM, $p=0.03$ ). Cheating is 13 percentage lower in $D R-L D$ compared to $D R-S D$ (BSM, $p=0.07$ ). Furthermore, cheating is 12 percentage lower in $I R-N D$ than in $D R-S D$ (BSM, $p=0.09$ ) and roughly 15 percentage lower in $D R-L D$ than in $I R-S$ (BSM, $p=0.02$ ). We test the theoretical predictions derived from our two theoretical frameworks (DEU and UAE) in Table A.1 and A.2. This can be found in Appendix A. Overall, our hypotheses are partially supported by both theoretical approaches. We discuss the implications in greater detail in the next section.

In order to check for robustness, we ran a series of regressions to analyze the behavioral motivations that result in cheating and the total amount of cheating that took place. Treating decisions across rounds in the fashion of panel data, our dependent

\footnotetext{
${ }^{9}$ We follow Moffatt (2015) and employ the bootstrap two-sample t-test method (hereafter BSM) with 9999 replications to analyze mean differences of average return behavior. This has the advantage that we can retain the rich cardinal information in the data without making any assumptions about the distribution. Unless noted otherwise, the use of non-parametric Mann-Whitney-U (hereafter MWU) tests yields results that are in line with our bootstrap approach.
} 


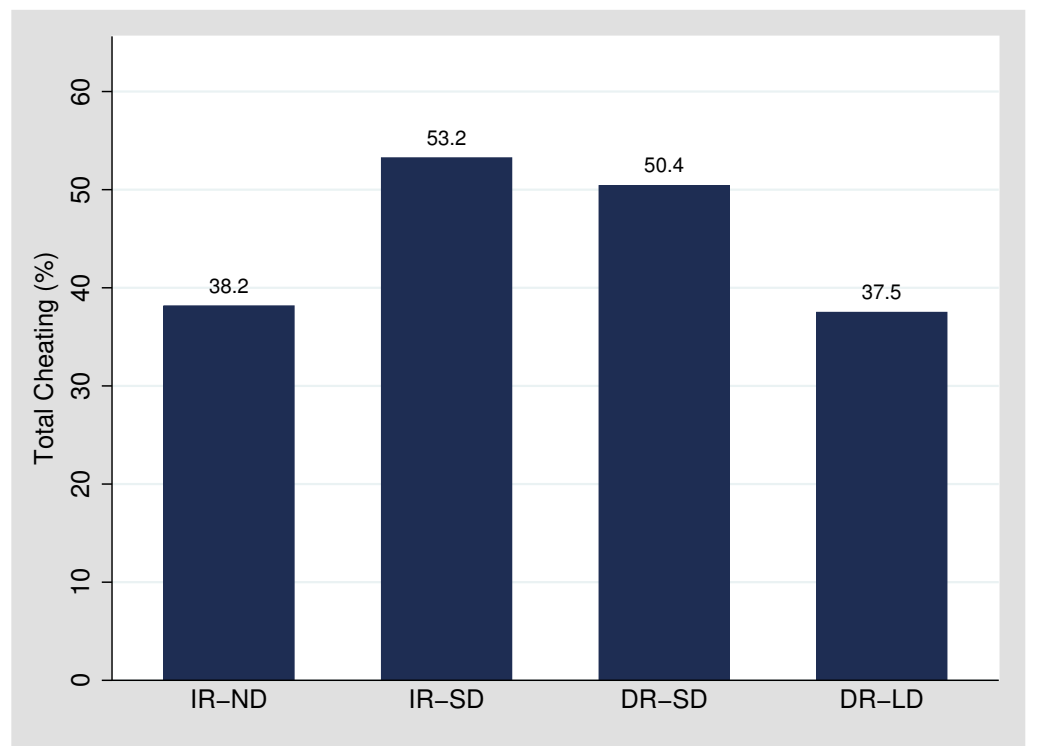

Figure 1: Total Cheating. Percentage of individual cheating attempts relative to the maximum of possible cheating attempts.

variable in Table 2 is a count variable adding up the total amount of cheating decisions across blocks. We present two types of regressions. The first analyzes behavior by timing (column 1) the second analyzes across treatment specifications. This allows us to dissect the impact of the timing of punishment from the timing of resolution of uncertainty, as well as, the effect of their interaction on total cheating behavior. To this end, we use $I R-S D$ with a short delay of punishment and no delayed resolution of uncertainty as our reference category. The extended form regressions (column 2) include a battery of relevant covariates (gender, age, number of correct card guesses, experience with punishment from past cheating, round indicator, risk tendencies, awareness of future consequences, self-control, and a dummy indicating a participant's previous participation in economic experiments).

Our analysis in Table 2 suggests that, relative to a short delay of punishment, both swifter and more delayed punishment renders individual cheating decisions significantly less likely. The introduction of delayed uncertainty resolution itself does not significantly affect cheating behavior. A direct comparison of our treatments mirrors this finding, indicating that higher deterrence can be achieved by either implementing swift punishment $(I R-N D)$ or through the combination of delayed uncertainty resolution and significantly delayed punishment $(D R-L D)$. Post estimation tests yield no difference between the coefficients of $I R-N D$ and $D R$ - $L D(p=0.88)$, suggesting that the effectiveness of deterrence is comparable in both cases. It is worth noting that we observe substantial gender het- 
Table 2: Total Cheating using GLS Random Effects Regressions

\begin{tabular}{|c|c|c|c|c|c|c|c|c|}
\hline \multirow{3}{*}{$\begin{array}{l}\text { TotalCheating } \\
\text { No Delay }\end{array}$} & \multicolumn{4}{|c|}{ Analysis by timing } & \multicolumn{4}{|c|}{ Analysis by treatment } \\
\hline & \multicolumn{2}{|c|}{ (1) } & \multicolumn{2}{|l|}{$(2)$} & \multicolumn{2}{|c|}{ (3) } & \multicolumn{2}{|l|}{ (4) } \\
\hline & $-0.3066^{* *}$ & $(0.1560)$ & $-0.3277^{* *}$ & $(0.1566)$ & & & & \\
\hline Long Delay & $-0.2849^{*}$ & $(0.1577)$ & $-0.2813^{*}$ & $(0.1582)$ & & & & \\
\hline Uncertainty & -0.0212 & $(0.1615)$ & -0.0437 & $(0.1643)$ & & & & \\
\hline IR-ND & & & & & $-0.3066^{* *}$ & $(0.1560)$ & $-0.3277^{* *}$ & $(0.1566)$ \\
\hline DR-SD & & & & & -0.0212 & $(0.1615)$ & -0.0437 & $(0.1643)$ \\
\hline DR-LD & & & & & $-0.3062^{* *}$ & $(0.1527)$ & $-0.3250^{* *}$ & $(0.1523)$ \\
\hline Male & $0.4020^{* * *}$ & $(0.1147)$ & $0.4361^{* * *}$ & $(0.1252)$ & $0.4020^{* * *}$ & $(0.1147)$ & $0.4361^{* * *}$ & $(0.1252)$ \\
\hline Age & $-0.4847^{* * *}$ & $(0.1671)$ & $-0.4800^{* * *}$ & $(0.1816)$ & $-0.4847^{* * *}$ & $(0.1671)$ & $-0.4800^{* * *}$ & $(0.1816)$ \\
\hline GuessCorrect & -0.0668 & $(0.0681)$ & -0.0510 & $(0.0693)$ & -0.0668 & $(0.0681)$ & -0.0510 & $(0.0693)$ \\
\hline Punishment & $0.3404^{* * *}$ & $(0.1157)$ & $0.2881^{* * *}$ & $(0.0689)$ & $0.3404^{* * *}$ & $(0.1157)$ & $0.2881^{* * *}$ & $(0.0689)$ \\
\hline Round & & & $0.4263^{* * *}$ & $(0.0242)$ & & & $0.4263^{* * *}$ & $(0.0242)$ \\
\hline Risk & & & -0.0625 & $(0.0624)$ & & & -0.0625 & $(0.0624)$ \\
\hline FutCons & & & -0.0249 & $(0.0610)$ & & & -0.0249 & $(0.0610)$ \\
\hline SelfControl & & & -0.0692 & $(0.0595)$ & & & -0.0692 & $(0.0595)$ \\
\hline ExpParticipation & & & 0.1472 & $(0.1204)$ & & & 0.1472 & $(0.1204)$ \\
\hline Constant & $1.1450^{* * *}$ & $(0.1373)$ & -0.0318 & $(0.1545)$ & $1.1450^{* * *}$ & $(0.1373)$ & -0.0318 & $(0.1545)$ \\
\hline Observations & 118 & & 118 & & 118 & & 118 & \\
\hline
\end{tabular}

Note: Standard errors in parentheses and clustered at the individual level. ${ }^{*} p<0.1,{ }^{* *} p<0.05,{ }^{* * *} p<$ 0.01. Reference categories are Short Delay and IR-SD, respectively. Age is 1 for participants older than 40 years. Higher values for Risk, Future Consequences, and Self-Control depict higher willingness to take risks, to be forward-looking and to exhibit higher self-control, respectively. These values are standardized. Total Punishment relates to the overall frequency of inflicted punishment on the individual if caught cheating.

erogeneity indicating that males cheat significantly more than females. The results also suggest that deviant behavior increases with punishment inflicted for caught cheating. This finding indicates that individuals try to make up for incurred losses by increasing the frequency of cheating and taking larger risks, thus being more risk-seeking in losses. Additionally, a participant's age is inversely and significantly correlated with cheating, while our other covariates cannot explain deviant behavior in our sample. Noteworthy, the amount of correct guesses in non-cheating rounds, which are the driving force behind wealth accumulation in our setting, has no significant predictive power for cheating. This indicates that potential wealth effects cannot explain cheating behavior. All this suggests that swifter punishment or delayed punishment in combination with delayed resolution of uncertainty significantly increases the deterrence of deviant behavior. The delay of uncertainty alone remains non-effective. We present the results in Table 2.

We conclude that both very efficient (no delays of punishment) and very inefficient (long delays of punishment in combination with long uncertainty about the status of discovery) punishment institutions are equally effective in deterring deviant behavior. 


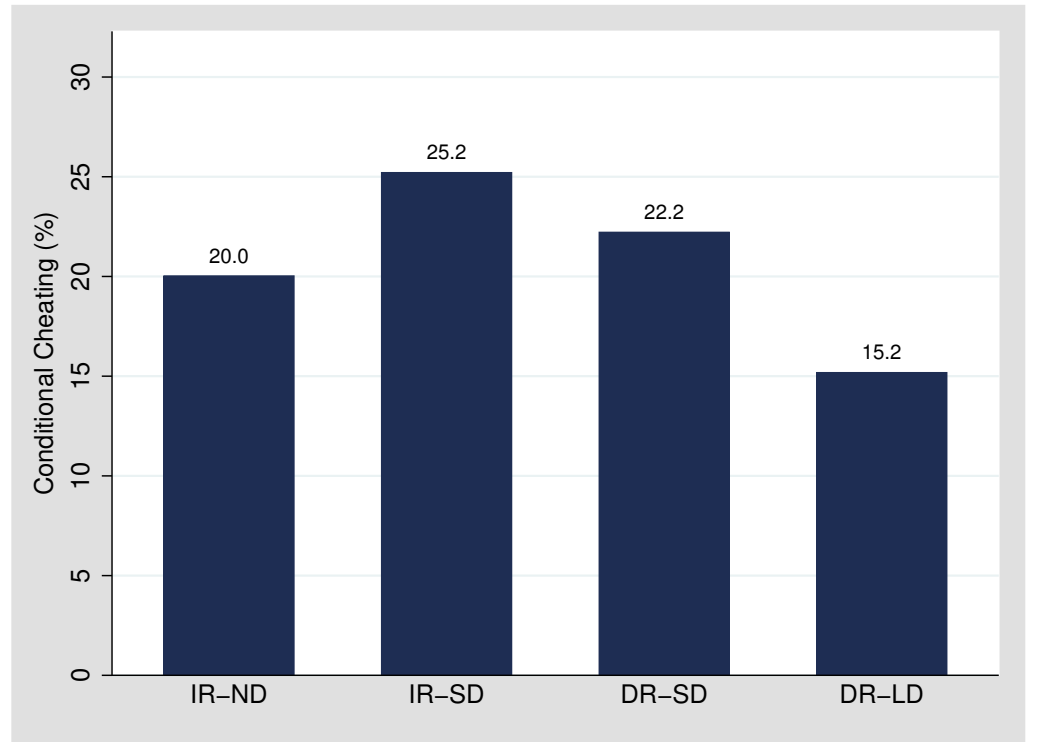

Figure 2: Conditional Cheating. Percentage of individual cheating attempts relative to the maximum of possible cheating attempts following their first cheating decision.

It is worth noting that one could also plausibly assume the presence of learning effects. A large body of existing literature suggests that the learning effects that emerge through experience are shaped by the timing of rewards and punishments. Due to this, they affect subsequent behavior (cf. Camp et al., 1967; Parke and Deur, 1972). This is of particular importance in the punishment context, because such learning effects would directly speak to the occurrence of recidivism among former felons. Following this logic, the experience of uncertainty and punishment following transgressive behavior could lead to differences in subsequent transgressions. We call this Conditional Cheating. Conditional Cheating is defined as the number of individual cheating decisions that proceed the first cheating decision (which can occur at the beginning of any of the first three blocks). The idea behind this measure is to understand whether experiencing the drain of uncertainty of punishment following their first cheating decision will affect the individual's subsequent propensity to cheat. Our results do not indicate that any such learning effect exists. In fact, cheating behavior following the experience of uncertainty and punishment is congruent to our previous findings on general cheating behavior. We present a graphical illustration in Figure 2.

In order to shed light on this mechanism, we employ a series of OLS regressions. Through these regressions we look to analyze the total amount of cheating that took place following the individual's first cheating decision and any resulting punishment that he or she incurred. In our attempt to proxy recidivism, our dependent variable measures 
Table 3: Conditional Cheating using OLS

\begin{tabular}{|c|c|c|c|c|c|c|c|c|}
\hline \multirow{3}{*}{$\begin{array}{l}\text { ConditionalCheating } \\
\text { No Delay }\end{array}$} & \multicolumn{4}{|c|}{ Analysis by timing } & \multicolumn{4}{|c|}{ Analysis by treatment } \\
\hline & \multicolumn{2}{|l|}{ (1) } & \multicolumn{2}{|c|}{ (2) } & \multicolumn{2}{|c|}{ (3) } & \multicolumn{2}{|l|}{ (4) } \\
\hline & $-0.1666^{* *}$ & $(0.0742)$ & $-0.1757^{* *}$ & $(0.0743)$ & & & & \\
\hline Long Delay & $-0.2129^{* *}$ & $(0.0844)$ & $-0.1932^{* *}$ & $(0.0851)$ & & & & \\
\hline Uncertainty & -0.0782 & $(0.0709)$ & -0.0871 & $(0.0717)$ & & & & \\
\hline IR-ND & & & & & $-0.1666^{* *}$ & $(0.0742)$ & $-0.1757^{* *}$ & $(0.0743)$ \\
\hline DR-SD & & & & & -0.0782 & $(0.0709)$ & -0.0871 & $(0.0717)$ \\
\hline DR-LD & & & & & $-0.2911^{* * *}$ & $(0.0785)$ & $-0.2803^{* * *}$ & $(0.0789)$ \\
\hline Male & 0.0881 & $(0.0570)$ & $0.1178^{*}$ & $(0.0625)$ & 0.0881 & $(0.0570)$ & $0.1178^{*}$ & $(0.0625)$ \\
\hline Age & -0.1298 & $(0.1033)$ & -0.1362 & $(0.1083)$ & -0.1298 & $(0.1033)$ & -0.1362 & $(0.1083)$ \\
\hline GuessCorrect & $-0.0831^{* *}$ & $(0.0348)$ & $-0.0830^{* *}$ & $(0.0360)$ & $-0.0831^{* *}$ & $(0.0348)$ & $-0.0830^{* *}$ & $(0.0360)$ \\
\hline Punishment & 0.0759 & $(0.0738)$ & 0.0684 & $(0.0736)$ & 0.0759 & $(0.0738)$ & 0.0684 & $(0.0736)$ \\
\hline Risk & & & -0.0185 & $(0.0306)$ & & & -0.0185 & $(0.0306)$ \\
\hline FutCons & & & 0.0343 & $(0.0313)$ & & & 0.0343 & $(0.0313)$ \\
\hline SelfControl & & & -0.0151 & $(0.0320)$ & & & -0.0151 & $(0.0320)$ \\
\hline ExpParticipation & & & 0.0691 & $(0.0627)$ & & & 0.0691 & $(0.0627)$ \\
\hline Constant & $0.7549^{* * *}$ & $(0.0587)$ & $0.6975^{* * *}$ & $(0.0762)$ & $0.7549^{* * *}$ & $(0.0587)$ & $0.6975^{* * *}$ & $(0.0762)$ \\
\hline Observations & 189 & & 189 & & 18 ! & & 189 & \\
\hline
\end{tabular}

Note: Odds ratio reported. Standard errors in parentheses and clustered on the individual level. ${ }^{*} p<$ $0.1{ }^{* *} p<0.05,{ }^{* * *} p<0.01$. Reference categories are Short Delay and IR-SD, respectively. Age is 1 for participants older than 40 years. Higher values for Risk, Future Consequences, and Self-Control depict higher willingness to take risks, to being forward-looking and to exhibit higher self-control, respectively. These values are standardized. Total Punishment relates to the overall frequency of inflicted punishment on the individual if caught cheating.

the amount of cheating that occured after one's first cheating decision. The less frequent or the later participants recidivise, the lower the value of our dependent variable.

Our results for conditional cheating are consistent with our previous findings, suggesting that the recidivism of individuals is lowest when punishment is either immediate or late when paired with uncertainty. The delay of uncertainty alone is non-effective. In particular, relative to immediate resolution and immediate punishment, a short-term delay of punishment $(I R-S D)$ leads to a significant increase in deviant behavior, while the additional introduction of uncertainty $(D R-S D)$ alone does not affect cheating rates relative to $I R-N D$. We again find an inverted $\mathrm{u}$-shape relationship; when combining the long delay of punishment with uncertainty of resolution, cheating rates return to levels similar to those found when immediate punishment is paired with no uncertainty resolution $(I R-N D)$. In support of this, post estimation tests show that the drop in cheating rates in $D R$ - $L D$ is significant compared to cheating in $I R-S D(p<0.01)$ and $D R-S D(p=0.02)$. In contrast to total cheating behavior, we do not observe robust gender heterogeneity or a traceable impact of age, self-control or experienced punishment. The latter finding indicactes that it is not the experience of total punishment that affects recidivism rates, 
but the combined initial experience of uncertainty and timing of punishment.

In summary, we can conclude that the same institutional settings that are capable of reducing recidivism are also the ones deterring deviant behavior in the first place. Our results demonstrate that swift or sufficiently delayed punishment, where the latter is accompanied by an extensive dread of uncertainty regarding one's detection, reduces future criminal behavior.

\section{Discussion and Conclusion}

We investigate along two dimensions how timing can impact the effectiveness of sanctions. We use a controlled laboratory experiment designed to study the effect of delayed punishment and delayed resolution of uncertainty on deterrence. Our experimental findings show that the timing of resolution of uncertainty has no effect on deterrence. For the delay of punishment, we observe the following inverted u-shape relationship: deterrence is highest for no delay or a large delay of punishment and lowest for a short delay of punishment.

The observed inverted u-shape is at odds with both discounted expected utility theory and anticipatory utility theory. According to the first theory, deterrence should decrease monotonically with the delay of punishment. According to the second, there should also be a monotonous relation between deterrence and delay which would be the inverse of that in the previous case if the effect of anticipation is sufficiently high. Recently, Baucells and Bellezza (2016) proposed a new theory of inter-temporal decision making. They extend the existing models of anticipatory utility by a reference point which adjusts. It does so during the anticipation phase by altering a utility of recall in the periods succeeding the consumption and changing the magnitude effect in discounting. In this theory it is possible that the utility maximizing timing of an unpleasant event is somewhere in the middle of the time horizon, i.e. fines in earlier or later periods hurt more and should, therefore, lead to higher deterrence. While our experiment was not designed to test the theory of Baucells and Bellezza (2016) it is the only theory which is compatible with the findings of our experiment.

It is important to note that the effects of the treatments on the total cheating behavior can be obtained by two different, possibly simultaneously operating processes. First, the variations in the experimental treatments could have affected anticipatory reasoning in the participants about how a possible punishment would impact them. If the impact is anticipated to be severe, this could lead to no or delayed cheating. Second, learning processes may have affected cheaters (who (at least once) underwent the respective treat- 
ments) differently by experiencing the (non)waiting for a resolution of uncertainty and the potential execution of an immediate or delayed punishment. This may have influenced their likelihood to cheat again in the future. Inspecting the results for conditional cheating (i.e. future cheating upon having cheated before) shows that they closely mirror the results of the total cheating behavior. Even if some experience for the treatments to become effective would be needed, basic learning theories (e.g. Azrin, 1956; Banks and Vogel-Sprott, 1965) are at odds with the inverted u-shaped relation between deterrence and delay of punishment which is also observed for conditional cheating. Arguably, the highly effective deterrence of deviant behavior in $D R-L D$ could be interpreted in one of the following two ways: one, only an extensive delay of punishment, and not the existence of uncertainty resolution, is responsible for the decrease in cheating; two, it is the combination of both the extensive delay in punishment and the existence of uncertainty that imposes additional dread and, thus, the interaction of both is driving the strength of deterrence. Our regression analysis and theoretical foundation suggests that it is most likely the former. We consider this as a promising venue for future research.

Our findings yield important insights for optimally designing sanctioning schemes in legal systems. Existing deterrence literature has almost exclusively focused on the role of severity and certainty of legal consequences in deterring proscribed actions. Our study shows that celerity, the timing of sanctions through sentencing, may also be a crucial component of an effective legal system. Our results imply that punishment should either follow the criminal act quickly or be sufficiently delayed if deterrence is to be maximized. As immediate punishment may be relatively costly, an optimally delayed punishment could be the most efficient solution.

Our study provides a first step into analyzing the effects of deterrence in a sanctioning system. In order to make conclusions for an optimal policy in the real world, future research needs to tackle several limitations of our study. In particular, it seems necessary to study celerity when the delay of punishment extends to the real payout of subjects. Also, the optimal delay may be very sensitive to the type of punishment, e.g. the optimal delay may be rather different for monetary fines than for imprisonment. Despite these limitations we think that our study highlights the role of celerity in designing optimal sanctioning systems and points to fruitful avenues for future research.

\section{References}

Abbink, K. (2004): "Staff Rotation as an Anti-Corruption Policy: an Experimental Study," European Journal of Political Economy, 20, 887-906. 
(2006): "14 Laboratory experiments on corruption," in The International Handbook on the Economics of Corruption, ed. by S. Rose-Ackermann, Edward Elgar, $418-438$.

Abbink, K., U. Dasgupta, L. Gangadharan, and T. Jain (2014): "Letting the Briber Go Free: an Experiment on Mitigating Harassment Bribes," Journal of Public Economics, 111, 17-28.

Acemoglu, D., S. Johnson, And J. Robinson (2005): "The Rise of Europe: Atlantic Trade, Institutional Change, and Economic Growth," The American economic review, $95,546-579$.

AzRin, N. H. (1956): "Some Effects of Two Intermittent Schedules of Immediate and Non-Immediate Punishment," The Journal of Psychology, 42, 3-21.

Bailey, W. C. (1980): "Deterrence and the Celerity of the Death Penalty: A Neglected Question in Deterrence Research," Social Forces, 58, 1308-1333.

Baker, T., A. Harel, And T. Kugler (2004): "The Virtues of Uncertainty in Law: An Experimental Approach," Iowa Law Review, 89, 443.

Banks, R. K. And M. Vogel-Sprott (1965): "Effect of Delayed Punishment on an Immediately Rewarded Response in Humans," Journal of Experimental Psychology, 70,357 .

Baucells, M. and S. Bellezza (2016): "Temporal Profiles of Instant Utility during Anticipation, Event, and Recall," Management Science, 63, 729-748.

Becker, G. S. (1968): "Crime and Punishment: An Economic Approach," Journal of Political Economy, 76, 169-217.

Bee, C. C. And R. Madrigal (2013): "Consumer Uncertainty: The Influence of Anticipatory Emotions on Ambivalence, Attitudes, and Intentions," Journal of Consumer Behaviour, 12, 370-381.

Buckenmaier, J., E. Dimant, And L. Mittone (2017): "Experimental Evidence on Tax Evasion, Corruption and and Incentives to Blow the Whistle," Mimeo.

Camp, D. S., G. A. Raymond, and R. M. Church (1967): "Temporal Relationship Between Response and Punishment," Journal of Experimental Psychology, 74, 114. 
Caplin, A. And J. Leahy (2001): "Psychological Expected Utility Theory and Anticipatory Feelings," The Quarterly Journal of Economics, 116, 55-79.

Chalfin, A. And J. McCrary (2017): "Criminal Deterrence: A Review of the Literature," Journal of Economic Literature, 55, 5-48.

DeAngelo, G. And G. Charness (2012): "Deterrence, Expected Cost, Uncertainty and Voting: Experimental Evidence," Journal of Risk and Uncertainty, 44, 73-100.

Dillenberger, D. (2010): "Preferences for One-Shot Resolution of Uncertainty and Allais-Type Behavior," Econometrica, 78, 1973-2004.

Ehrlich, I. (1996): "Crime, Punishment, and the Market for Offenses," The Journal of Economic Perspectives, 10, 43-67.

Engel, C. (2016): "Experimental Criminal Law. A Survey of Contributions from Law, Economics and Criminology," Mimeo.

Engel, C., S. J. Goerg, And G. Yu (2016): "Symmetric vs. Asymmetric Punishment Regimes for Collusive Bribery," American Law and Economics Review, 18, 506-556.

Falk, A. And F. Zimmermann (2016): "Beliefs and Utility: Experimental Evidence on Preferences for Information," Mimeo.

Fischbacher, U. (2007): "z-Tree: Zurich Toolbox for Ready-Made Economic Experiments," Experimental economics, 10, 171-178.

Frederick, S., G. Loewenstein, and T. O'Donoghue (2002): "Time Discounting and Time Preference: A Critical Review," Journal of Economic Literature, 40, 351401.

Golman, R. And G. Loewenstein (2015): "The Demand For, and Avoidance of, Information," .

Hackenberg, T. D. (2009): "Token Reinforcement: A Review and Analysis," Journal of the Experimental Analysis of Behavior, 91, 257-286.

Howe, E. S. And C. J. Brandau (1988): "Additive Effects of Certainty, Severity, and Celerity of Punishment on Judgments of Crime Deterrence Scale Value," Journal of Applied Social Psychology, 18, 796-812. 
Kocher, M. G., M. Krawczyk, and F. van Winden (2014): "Let Me Dream on! Anticipatory Emotions and Preference for Timing in Lotteries," Journal of Economic Behavior and Organization, 98, 29-40.

Kogler, C., L. Mittone, And E. Kirchler (2016): "Delayed Feedback on Tax Audits Affects Compliance and Fairness Perceptions," Journal of Economic Behavior E Organization, 124, 81-87.

Kreps, D. M. And E. L. Porteus (1978): "Temporal Resolution of Uncertainty and Dynamic Choice Theory," Econometrica, 46, 185-200.

La Porta, R., F. Lopez-de Silanes, A. Shleifer, and R. Vishny (1999): "The Quality of Government," The Journal of Law, Economics, and Organization, 15, 222279 .

Loewenstein, G. (1987): "Anticipation and the Valuation of Delayed Consumption," The Economic Journal, 97, 666-684.

Lovallo, D. and D. Kahneman (2000): "Living with Uncertainty: Attractiveness and Resolution Timing," Journal of Behavioral Decision Making, 13, 179.

Moffatt, P. G. (2015): Experimetrics: Econometrics for Experimental Economics, Palgrave Macmillan.

Nagin, D. S. And G. Pogarsky (2001): "Integrating Celerity, Impulsivity, and Extralegal Sanction Threats into a Model of General Deterrence: Theory and Evidence," Criminology, 39, 865-892.

- (2004): "Time and Punishment: Delayed Consequences and Criminal Behavior," Journal of Quantitative Criminology, 20, 295-317.

Parke, R. D. And J. L. Deur (1972): "Schedule of Punishment and Inhibition of Aggression in Children," Developmental Psychology, 7, 266.

Paternoster, R. (2010): "How Much Do We Really Know About Criminal Deterrence?" The Journal of Criminal Law and Criminology, 765-824.

Shleifer, A. And R. W. Vishny (1993): "Corruption," The Quarterly Journal of Economics, 108, 599-617.

Skinner, B. F. (1963): "Operant Behavior," American Psychologist, 18, 503. 
Strathman, A., F. Gleicher, D. S. Boninger, and C. S. Edwards (1994): "The Consideration of Future Consequences: Weighing Immediate and Distant Outcomes of Behavior," Journal of Personality and Social Psychology, 66, 742.

Strzalecki, T. (2013): "Temporal Resolution of Uncertainty and Recursive Models of Ambiguity Aversion," Econometrica, 81, 1039-1074.

Tangney, J. P., R. F. Baumeister, And A. L. Boone (2004): "High Self-Control Predicts Good Adjustment, Less Pathology, Better Grades, and Interpersonal Success," Journal of personality, 72, 271-324.

Tversky, A. And D. Kahneman (1986): "Rational Choice and the Framing of Decisions," Journal of business, S251-S278.

Wu, G. (1999): “Anxiety and Decision Making with Delayed Resolution of Uncertainty," Theory and Decision, 46, 159-199.

Yu, J. (1994): "Punishment Celerity and Severity: Testing a Specific Deterrence Model on Drunk Driving Recidivism," Journal of Criminal Justice, 22, 355-366. 


\section{A Overview Predictions for DEU and UAE}

Table A.1: Predictions for Total Cheating under DEU

\begin{tabular}{c|c|c|c}
\hline \hline \multicolumn{4}{c}{ DEU } \\
\hline Hypothesis & Predictions & Confirmed? & Sign. Level \\
\hline H1 & $I R-S D>I R-N D$ & Yes & $* *$ \\
& $D R-L D>D R-S D$ & No & - \\
\hline H2 & $I R-S D=D R-S D$ & Yes & Not rejected \\
\hline H3 & $D R-S D>I R-N D$ & Yes & $* *$ \\
& $D R-L D>I R-S D$ & No & - \\
\hline \hline
\end{tabular}

Note: Significance levels are the result of one-sided t-tests examining the direction of mean differences based on the theoretical predictions.

Table A.2: Predictions for Total Cheating under UAE

\begin{tabular}{c|c|c|c}
\hline \hline \multicolumn{4}{c}{ UAE } \\
\hline Hypothesis & Predictions & Confirmed? & Sign. Level \\
\hline H1 & $I R-S D<I R-N D$ & No & - \\
& $D R-L D<D R-S D$ & Yes & $* *$ \\
\hline $\mathrm{H}^{*}$ & $D R-S D<I R-S D$ & No & - \\
\hline $\mathrm{H}^{*}$ & $D R-S D<I R-N D$ & No & - \\
\hline $\mathrm{H}^{*}$ & $D R-L D<I R-S D$ & Yes & $* * *$ \\
& $D R-L D<I R-N D$ & No & - \\
\hline \hline
\end{tabular}

Note: Significance levels are the result of one-sided t-tests examining the direction of mean differences based on the theoretical predictions. 


\section{B Instructions}

\section{General Instructions}

Welcome to the Lab! You are about to participate in an experiment on decision-making. During the experiment you can earn money. The amount of money you will earn depends on your decisions during the session. The session consists of 28 rounds. Your earnings are determined by the sum of your earnings in each round. During the experiment all amounts will be presented in ECU (Experimental Currency Unit). At the end of the experiment all the ECU you have earned will be converted to Dollars as follows:

$$
10 \mathrm{ECU}=1 \$
$$

At the end of the experiment your total earnings, which is the amount you have earned during the session (converted to Dollars), will be privately paid to you in cash.

Additionally, there is a separate charity fund for each participant, which initially contains 250 ECU. Your decisions during the experiment will affect the final amount of ECU in your charity fund. At the end of this session, one participant will be randomly chosen and the final amount of ECU that remain in that participant's charity fund will be donated to "Doctors without Borders" (for more information on the work and the mission of Doctors without Borders please find enclosed the summary taken from their website). Therefore, if you are selected your decisions throughout the experiment would directly affect the amount of money that is actually donated. A copy of the receipt of the donations can be made available upon demand.

If there is something you do not understand or if you have any questions, now or at some point during the experiment, please raise your hand and remain seated. One of our colleagues will come to you and answer your question.

It is important that you read all instructions and explanations on the screen carefully before making your decision.

For the purpose of the experiment it is important that you do not talk or communicate in other ways with the other participants. Please turn off your cell phone and all other electronic devices.

After the actual experiment concludes, we will ask you to fill out a questionnaire. Please fill out the questionnaire carefully and truthfully. The whole experiment is completely anonymous and your answers cannot be traced back to you personally. Therefore, it is important that you fill out the questionnaire carefully even if you have already answered a similar questionnaire in another experiment in the past. 


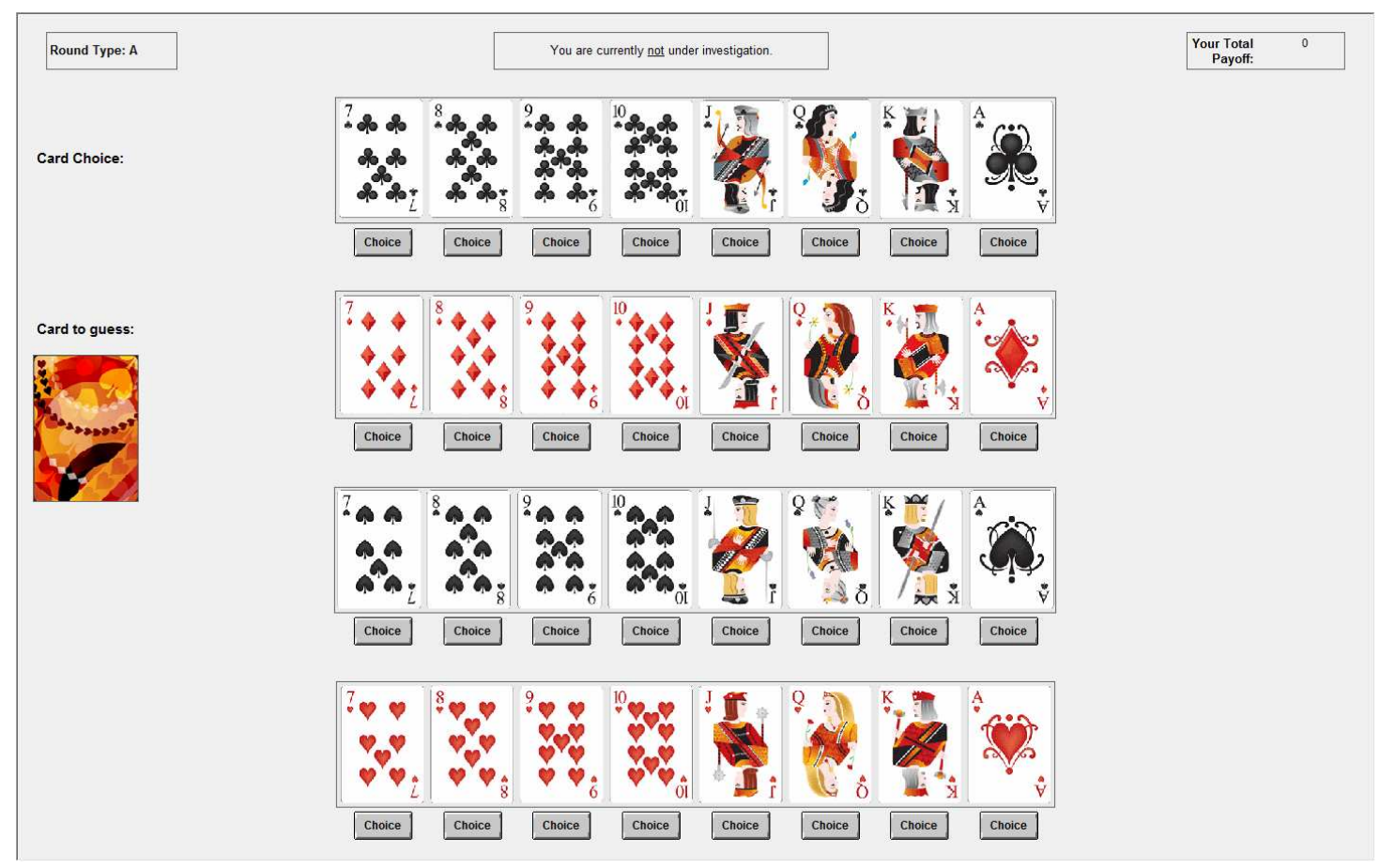

Figure 1

On the next pages you will receive further information regarding the experiment and your decisions.

\section{Experiment Instructions}

In this experiment you have to make a series of decisions over 28 rounds. In each round the computer will draw a single card from a deck of cards. The deck contains the 32 cards shown in Figure 1 below. Each card is drawn with the same probability.

There are two different types of rounds, type A and type B. This means any of the 28 rounds is either of type A or type B. For each round the round type is indicated on the computer screen at the top left corner. We detail the course of events for each type of round below.

\section{Type A}

In rounds of type A you have to play the "guessing game" where you have to guess which card was randomly drawn by selecting the corresponding card from the 32 cards shown on your screen (see Figure 1 above). For a correct guess, that is if the card you have chosen is the exact same card drawn by the computer in suit and number, 
you will receive a payout of 10 ECU. For an incorrect guess, that is the computer has drawn a card different from the one you have chosen, you will receive a payout of 4 ECU.

\section{Example:}

1. Suppose your guess is "King Of Hearts", i.e. you have chosen "King Of Hearts" on the screen in Figure 1, and the card actually drawn by the computer is "King Of Hearts". This means you guessed correctly and 10 ECU is added to your account.

2. Suppose your guess is "King Of Hearts" and the card actually drawn by the computer is "Queen Of Spades". This means you guessed incorrectly and 4 ECU is added to your account.

3. Suppose your guess is "King of Hearts" and the card actually drawn by the computer is "King of Clubs." This means you guess incorrectly and 4 ECU is added to your account.

\section{Type B}

In rounds of type B you first have to decide whether you want to follow the rules of the guessing game or cheat in the guessing game. If you choose to cheat, the computer will guess the right card for you. In other words:

- If you decide to follow the rules, you can make your guess just as in rounds of type A with the same possible payouts, i.e. if you guess correctly you receive 10 ECU and if you guess incorrectly you receive 4 ECU.

- If you decide to cheat, you do not have to guess which card was drawn, but the computer will automatically choose the right card for you. This means when you choose to cheat you will always "guess" correctly and win 10 ECU. However, when you cheat an amount of $50 \mathrm{ECU}$ will be subtracted from the charity pool, i.e. every time you cheat the amount of money that will be donated to "Doctors without borders" is reduced by 50 ECU. This reduction in the charity fund will become a reality in the case that your decisions are randomly chosen to determine the ending amount in the charity fund at the conclusion of the experiment.

Any instance of cheating will be investigated. Cheating is detected with a probability of $25 \%$. This means that one out of four times you will be detected. The investigation is completed in the same round. When the investigation is completed you are informed whether your cheating was detected or not. 
If your cheating was detected, you will be suspended for one round and you have to pay a fine of 10 ECU. When suspended you can neither cheat nor guess and will not earn any ECU in that round. Moreover, the fine of 10 ECU will be deducted from your account in the round you are suspended. Your suspension will be implemented in the first round after the investigation is completed and your cheating is detected (see the timeline in Figure 2 below). This does not affect any other round except the round of your suspension.

There are no more than five type B rounds.

\section{Examples:}

Situation 1: Suppose we are in round 7 and this is a round of type A.

There are two possible payouts for this round, which depend on your guess:

1. You guessed correctly (your guess and the computers draw coincide). You earn 10 ECU in round 7.

2. You guessed incorrectly (your guess and the computers draw do not coincide). You earn 4 ECU in round 7.

Situation 2: Suppose we are in round 7 and this is a round of type B.

There are four possible payouts for this round, which depend on whether you cheat, are detected upon investigation, and, in case you did not cheat also on your guess:

1. You did not cheat and guessed correctly. You earn 10 ECU in round 7. There are no other consequences.

2. You did not cheat and guessed incorrectly. You earn 4 ECU in round 7. There are no other consequences.

3. You cheated and $10 \mathrm{ECU}$ are added to your account in round 7. The investigation reveals in round 7 that you were not detected and do not face any further consequences.

Because you cheated an amount of 50 ECU will be deducted from the charity pool if your decisions are chosen to determine the charity fund. 
4. You cheated and $10 \mathrm{ECU}$ are added to your account in round 7. The investigation reveals in round 7 that you were detected. You will be suspended for round 8, further you have to pay a fine of 10 ECU which will deducted from your account during your suspension in round 8 . This means in round 8 you cannot make any decision, but the fine of 10 ECU will be deducted from your account.

Because you cheated an amount of 50 ECU will be deducted from the charity pool if your decisions are chosen to determine the charity fund.

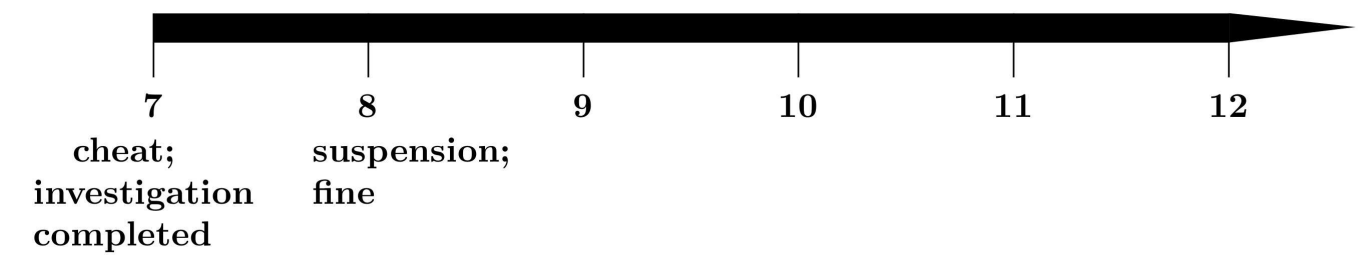

\section{Summary}

We now summarize the course of action for a single round:

1. If you are suspended for this round a pop-up screen will inform you that you are not allowed to make any decisions in this period. Please wait for the next round to proceed.

2. In rounds of type A you have to play the guessing game (see Figure 1).

3. In rounds of type B you have to decide whether you want to cheat or follow the rules. If you cheat the computer selects the right card for you. If you do not cheat you play the guessing game as in rounds of type A.

4. After you have made your decisions the outcome screen appears where you are informed of the outcome of this round and your payoff. If an investigation is completed you are informed about the outcome and consequences.

5. If you were detected for cheating, your punishment consists of a) losing the $10 \mathrm{ECU}$ you won by engaging in elicit behavior, b) you have to pause for the next round (60 seconds waiting time), and c) you forgo the potential income of the round in which you are paused. 


\section{Comprehension Questions}

Please answer the following comprehension questions. If you have any questions, please raise your hand and remain seated. Somebody will come to you and answer your question.

QUESTION 1: In rounds of type A you have the option to cheat.

(Please circle the right answer.)

right

wrong

QUESTION 2: In rounds of type B you have the option to cheat.

(Please circle the right answer.)

right

wrong

QUESTION 3: How many ECU are added to your account if you cheat in that round?

QUESTION 4: What is the probability that you are detected after you cheated?

QUESTION 4: What is your payout if you guess correctly/incorrectly in the guessing game?

QUESTION 5: Suppose you cheated in round 7. In which round is the investigation completed and you are informed whether you have been detected or not?

(Please circle the right answer.)

round 7

round 8

QUESTION 6: Suppose you cheated in round 7 and the completed investigation has revealed that you have been detected. In which round are you suspended and the fine is deducted from your account?

(Please circle the right answer.)

round 7

round 8 